\title{
Pengembangan E-Modul Asam Basa Berbasis Literasi Sains
}

\section{The Development of Acid Base E-Module Based on Scientific Literacy}

\author{
$\mathrm{N} \mathrm{Ulfa}^{1^{*}}$ and A Sutiani ${ }^{1}$ \\ ${ }^{1}$ Pendidikan Kimia, Universitas Negeri Medan, \\ Jl. Wiliam Iskandar, Kenangan Baru, Deli Serdang, Sumatera Utara, Indonesia. 20221 \\ *nadyaulfa011@gmail.com
}

\section{ARTICLE INFO}

Received on:

29 September 2021

Revised till:

31 October 2021

\section{Accepted on:}

01 November 2021

Publisher version published on:

02 November 2021

\begin{abstract}
Teaching material is one of the aspects to improve scientific literacy skills had by students, but based on the analysis of school textbooks, especially on acid-base materials, two chemistry textbook do not yet have the maximum application of scientific literacy. The aim of this research is to develop acid base e-module based on scientific literacy. The method implemented is Research and Development $(R \& D)$ method by Borg and Gall which is limited to seven out of ten stages. The instrument used in this study was questionnaire of validity and practicality. Validation was carried out by five validators while the practicality test was distributed to two chemistry teachers and 20 students of Class XI Science of SMA Negeri 10 Medan. Based on the validation results obtained from the validators, the average result is 4,70 which a very feasible criteria. The average value of teachers and students practicality responses was 4,60 and 4,42 with a very feasible criteria so it was concluded the acid-base e-module based on scientific literacy is valid, practical and also feasible to be used in learning activities for high school students. The follow-up of this research is to conduct a trial of the effectiveness of using e-modules in improving students' scientific literacy skills.
\end{abstract}

\section{KEYWORDS}

Acid Base, E-Module, Scientific Literacy

\section{ABSTRAK}

Bahan ajar merupakan salah satu aspek untuk meningkatkan kemampuan literasi sains yang dimiliki siswa, namun berdasarkan analisis buku ajar sekolah khususnya pada materi asam basa, dua buku kimia sekolah belum memiliki penerapan literasi sains yang maksimal. Tujuan dari penelitian ini adalah untuk mengembangkan e-modul berbasis literasi sains pada materi asam basa. Metode penelitian yang diterapkan adalah Research and Development (R\&D) oleh Borg and Gall yang dibatasi hingga tujuh dari sepuluh tahapan. Instrumen yang digunakan dalam penelitian ini adalah angket validasi dan kepraktisan. Validasi dilakukan oleh lima orang validator sedangkan uji kepraktisan dilakukan oleh dua orang guru kimia dan 20 siswa kelas XI IPA SMA Negeri 10 Medan. Berdasarkan hasil validasi yang diperoleh dari validator diperoleh hasil rata-rata sebesar 4,70 dengan kriteria sangat layak. Nilai rata-rata tanggapan kepraktisan guru dan siswa adalah 4,60 dan 4,42 dengan kriteria sangat layak sehingga dapat disimpulkan e-modul asam basa berbasis literasi sains valid dan praktis serta layak digunakan dalam kegiatan pembelajaran siswa SMA. Tindak lanjut penelitian ini adalah dilakukannya uji coba efektivitas penggunaan e-modul dalam meningkatkan kemampuan literasi sains siswa.

\section{KATA KUNCI}

Asam Basa, E-Modul, Literasi Sains 


\section{PENDAHULUAN}

Abad 21 merupakan abad ilmu pengetahuan dengan tersebarnya informasi dan teknologi yang terus berkembang. Tantangan tersebut harus dihadapi oleh siswa dan guru agar tidak tertinggal, terutama dalam proses pembelajaran. Keterampilan literasi sains sangat dibutuhkan untuk menghadapi masalah abad 21 dalam pemecahan masalah kontekstual. Kemampuan ini dapat membantu penerapan pengetahuan peserta didik untuk memecahkan masalah dalam lingkup pribadi, sosial dan global ${ }^{[1]}$. Peneliti lain juga menyatakan bahwa literasi sains juga penting dalam dunia kerja yang akan dihadapi siswa. Literasi sains terbagi menjadi 3 dimensi besar, yaitu konten, proses, dan konteks/aplikasi sains ${ }^{[2]}$.

Berdasarkan hasil program PISA (Programme for International Student Assessment) tahun 2018, kemampuan literasi sains, membaca dan matematika siswa Indonesia berada pada level 10 terendah yaitu 70 dari 78 negara yang dievaluasi ${ }^{[3]}$. Selain model pembelajaran, pemilihan buku pembelajaran serta rendahnya literasi sains siswa juga menjadi faktor yang memengaruhi hasil literasi sains siswa ${ }^{[4]}$.

Literasi sains, menurut International Forum on Scientific and Technological Literacy for All, yang diselenggarakan oleh UNESCO pada tahun 1993, adalah kemampuan untuk mendapatkan pemahaman dan kepercayaan diri dengan membawa ide-ide ilmiah dan teknologi ${ }^{[1]}$. Literasi sains meliputi empat aspek yakni peran sains sebagai batang tubuh pengetahuan ( $a$ body of knowledge), peran sains sebagai cara untuk menyelidiki ( $a$ way of investigating), peran sains sebagai cara untuk berpikir ( $a$ way of thinking) dan interaksi antara sains, masyarakat, dan teknologi (Interaction of science, technology, and society) ${ }^{[5]}$.

Buku teks IPA biasanya menyajikan materi dalam bentuk teks untuk dihafal siswa daripada menyajikan proses untuk melibatkan siswa tentang bagaimana pengetahuan itu diperoleh. Sebagian besar indikator literasi sains dalam buku teks hanya diajarkan dengan membaca dan menulis saja ${ }^{[6]}$. Pada penelitian lain didapatkan dimensi aspek pengetahuan (isi) hanya mencapai $13,34 \%$, dimensi proses $14,44 \%$, dan dimensi konteks $15,32 \%{ }^{[7]}$.

Kemampuan literasi sains adalah salah satu kemampuan yang wajib dimiliki dan dikembangkan dalam mempelajari materi asam basa. Tujuan hal ini adalah agar siswa dapat memiliki informasi ilmiah dan berfikir ilmiah untuk memecahkan suatu fenomena alam yang berhubungan dengan konsep asam basa. Literasi sains merupakan salah satu parameter dalam menentukan indeks peningkatan sumber daya manusia yang dipengaruhi oleh kualitas pendidikan $^{[8]}$.

Materi asam basa terdapat dalam mata pelajaran kimia yang mana memiliki kontribusi cukup besar dalam penanaman konsep dasar untuk menguasai materi di tingkat lanjutan. Upaya yang dapat dilakukan untuk mengoptimalkan kemampuan siswa dalam menghadapi persaingan di era globalisasi adalah dengan menyediakan sumber belajar berbasis sains. Sumber belajar dengan konten literasi sains akan mendorong siswa memiliki keterampilan berpikir kritis dan keterampilan literasi informasi sehingga dapat menganalisis, mengevaluasi, dan mensintesis informasi untuk dipilah dan ditentukan informasi yang relevan dengan kebutuhannya ${ }^{[9-10]}$.

Pembelajaran menggunakan modul memberikan dampak positif terhadap siswa yaitu siswa mampu secara cepat menyelesaikan satu atau lebih kompetensi dasar ${ }^{[11]}$. Peningkatan kualitas pembelajaran perlu didukung dengan penggunaan media pembelajaran berbasis teknologi. Modul elektronik atau e-modul adalah salah satu inovasi pembelajaran berbasis teknologi yang dapat membuat suasana pembelajaran menjadi lebih menarik, interaktif, dapat diterapkan dimana saja dan kapan saja, serta mampu meningkatkan kualitas pembelajaran yang lebih baik ${ }^{[2-13]}$.

\section{METODE}

Jenis penelitian yang dilakukan adalah penelitian dan pengembangan (Research and Development) oleh Borg and Gall yang terdiri dari 10 tahap. Namun dalam penelitian ini dibatasi menjadi tujuh langkah saja untuk mengetahui kelayakan e-modul berdasarkan hasil penilaian validator dan melihat kepraktisan produk melalui respons guru dan siswa terhadap e-modul yang telah dikembangkan. Secara umum prosedur pengembangan e-modul dalam penelitian ini adalah 1) Penelitian dan Pengumpulan Informasi 2) Perencanaan 3) pengembangan 4) Uji Pertama (Validasi) 5) Revisi Produk Utama 6) Uji Terbatas (Kepraktisan) dan 7) Revisi Produk Operasional ${ }^{[14]}$. Subjek dalam penelitian ini adalah 3 orang dosen kimia FMIPA UNIMED, 4 orang guru kimia, dan 20 siswa kelas XI IPA SMA Negeri 10 Medan.

Pengumpulan data dalam penelitian ini menggunakan instrumen berupa lembar analisis buku ajar sekolah yang disusun berdasarkan aspek literasi sains, lembar validasi yang disusun berdasarkan BSNP dan aspek literasi sains, serta lembar respons penilaian kepraktisan yang semuanya menggunakan skala Likert 5 jawaban. Pengumpulan data dalam penelitian ini juga menggunakan teknik kuesioner. Pada dasarnya kuesioner adalah sejumlah pertanyaan yang harus diisi oleh orang yang akan diukur (responden). Rumus untuk menentukan interval jarak dari sangat buruk ke sangat baik dapat dilihat pada Persamaan 1. Berdasarkan jarak interval tersebut, tabel kriteria sikap responden terhadap e-modul yang dikembangkan dapat dilihat pada Tabel 1.

$$
x=\frac{\Sigma \mathrm{x}}{n} \ldots \text { Persamaan } 1 .
$$


Tabel 1. Interpretasi Kriteria Kelayakan E- Modul ${ }^{[15]}$.

\begin{tabular}{c|c} 
Rata-Rata & Kriteria Kelayakan \\
\hline $1,00-1,80$ & Sangat Tidak Layak \\
\hline $1,81-2,60$ & Tidak Layak \\
\hline $2,61-3,40$ & Cukup Layak \\
\hline $3,41-4,20$ & Layak \\
\hline $4,21-5,00$ & Sangat Layak
\end{tabular}

\section{HASIL DAN DISKUSI}

\subsection{Penelitian dan Pengumpulan Informasi}

Penelitian dan pengumpulan informasi dilakukan dengan wawancara kepada salah satu guru kimia di SMAN 10 Medan dengan hasil bahwa siswa mengalami permasalahan dalam penyelesaian latihan atau ulangan yang diberikan dengan menggunakan pemahamannya sendiri. Proses pembelajaran kimia juga terkesan monoton sehingga siswa mudah bosan dan kesulitan dalam memahami kimia, khususnya larutan asam basa.

Pada tahap ini juga dilakukan penilaian terhadap 3 buku SMA berdasarkan aspek literasi sains. Hasil penilaian ketiga buku berdasarkan komponen kelayakan literasi sains dapat dilihat pada Tabel 2. Analisis buku dilakukan secara khusus pada materi larutan asam basa dengan sub materi sebagai berikut: 1) teori asam basa, 2) indikator asam basa, 3) menghitung derajat keasaman ( $\mathrm{pH}), 4$ ) reaksi asam basa, dan 5) titrasi asam basa.

Nilai rata-rata yang diperoleh dari ketercapaian 4 aspek literasi sains pada buku A adalah 3,22 dengan kriteria "cukup layak", buku B dengan nilai rata-rata 3,60 pada kriteria "layak", dan buku C dengan nilai 4,32 pada kriteria "sangat layak".

\subsection{Perencanaan}

Pada tahap perancangan ini dilakukan dengan merancang seluruh komponen bahan ajar e-modul, juga meliputi penyesuaian kompetensi inti, kompetensi dasar dan silabus kurikulum 2013 serta pengumpulan sumber dan informasi terkait materi pembelajaran yang dapat mendukung pemahaman dan kemampuan literasi sains siswa.

\subsection{Pengembangan}

Tahap ini dilakukan dengan membuat desain e-modul asam basa berbasis literasi sains. E-modul yang dikembangkan disusun lengkap berdasarkan komponen-komponen modul dan beberapa penambahan lainnya yaitu: cover, pendahuluan yang meliputi Kompetensi Dasar (KD), tujuan pembelajaran, indikator pembelajaran dan petunjuk penggunaan e-modul, peta konsep, materi, contoh soal, lembar kerja siswa, lembar kegiatan yang meliputi eksperimen dengan aplikasi materi dalam kehidupan sehari-hari dan isu sosial, glosarium, sistem periodik unsur, rangkuman, tabel penilaian mandiri, kunci jawaban, daftar isi, daftar tabel, daftar gambar, dan daftar pustaka. Beberapa tampilan e-modul hasil pengembangan terdapat pada Gambar 1. E-modul ini dibuat menggunakan Microsoft Word yang selanjutnya diintegrasikan ke format pdf untuk memudahkan akses siswa.

\subsection{Uji Pertama (Validitas)}

Uji validitas dilakukan untuk mengetahui penilaian ahli terhadap rancangan pengembangan yang dibuat ${ }^{[16]}$. Penilaian dilakukan terhadap beberapa aspek yang terdiri dari aspek isi, aspek penyajian, aspek bahasa dan aspek literasi sains. Hasil uji validitas oleh ahli dapat dilihat pada Tabel 3.

Tabel 2. Hasil Penilaian Aspek Literasi Ilmiah Materi Asam-Basa dari Tiga Buku Kimia SMA.

\begin{tabular}{c|c|c|c|c|c}
\multirow{2}{*}{$\begin{array}{c}\text { Kode } \\
\text { Buku }\end{array}$} & $\begin{array}{c}\text { Sains sebagai } \\
\text { batang tubuh } \\
\text { pengetahuan }\end{array}$ & $\begin{array}{c}\text { Sains sebagai } \\
\text { cara untuk } \\
\text { menyelidiki }\end{array}$ & $\begin{array}{c}\text { Sains sebagai } \\
\text { cara untuk } \\
\text { berpikir }\end{array}$ & $\begin{array}{c}\text { Interaksi antara } \\
\text { sains, teknologi, } \\
\text { dan masyarakat }\end{array}$ & $\begin{array}{c}\text { Jumlah } \\
\text { Rata-Rata }\end{array}$ \\
\hline A & 3.50 & 3.56 & 2.56 & 3.25 & 3.22 \\
\hline B & 3.83 & 3.89 & 2.67 & 4.00 & 3.60 \\
\hline C & 4.67 & 4.78 & 3.44 & 4.38 & 4.32 \\
\hline
\end{tabular}

Tabel 3. Hasil Penilaian masing-masing kriteria dari kelima validator.

\begin{tabular}{c|l|c|c|c|c|c|c|l}
\multirow{2}{*}{ No. } & \multirow{6}{*}{ Aspek } & \multicolumn{5}{|c|}{ Validator } & \multirow{2}{*}{ Rata-Rata } & Kriteria kelayakan \\
\cline { 3 - 7 } & & $\mathbf{1}$ & $\mathbf{2}$ & $\mathbf{3}$ & $\mathbf{4}$ & $\mathbf{5}$ & & \\
\hline 1 & Konten & 4.58 & 4.17 & 4.83 & 4.83 & 4.58 & 4.60 & Sangat Layak \\
\hline 2 & Tampilan & 4.73 & 5.00 & 4.73 & 4.91 & 4.73 & 4.82 & Sangat Layak \\
\hline 3 & Bahasa & 4.42 & 4.42 & 4.58 & 4.67 & 4.75 & 4.57 & Sangat Layak \\
\hline 4 & Literasi Sains & 4.52 & 4.94 & 4.77 & 4.68 & 4.87 & 4.75 & Sangat Layak
\end{tabular}


Edukimia $\cdot 2021 \cdot$ Vol. 3, No. 3



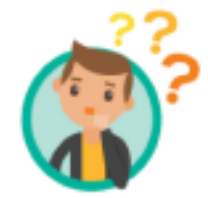

Ion hidrogen atau ion hidronium?

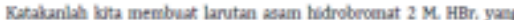
merupakan asan Antheneus. Apakah mu beratt lata memilikd $2 \mathrm{M}$ kn H* delan lantaa loce?

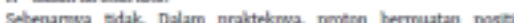

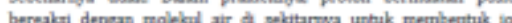
hidronium $\mathrm{B}_{1} \mathrm{O}^{\circ}$, Reakst ini dapat ditulis sebapal berikis



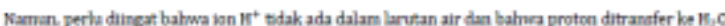

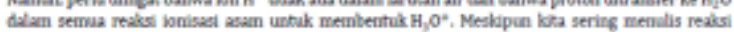



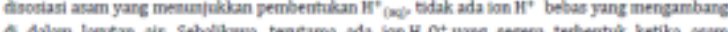


terdisceiasi dalam air, Gambar benkit nengzambarkan penbentukan hidronium dari air dan be

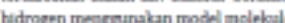

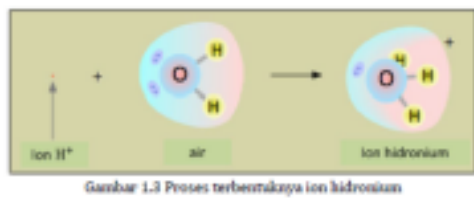



$$
\begin{aligned}
& \text { w }
\end{aligned}
$$

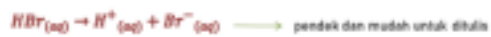
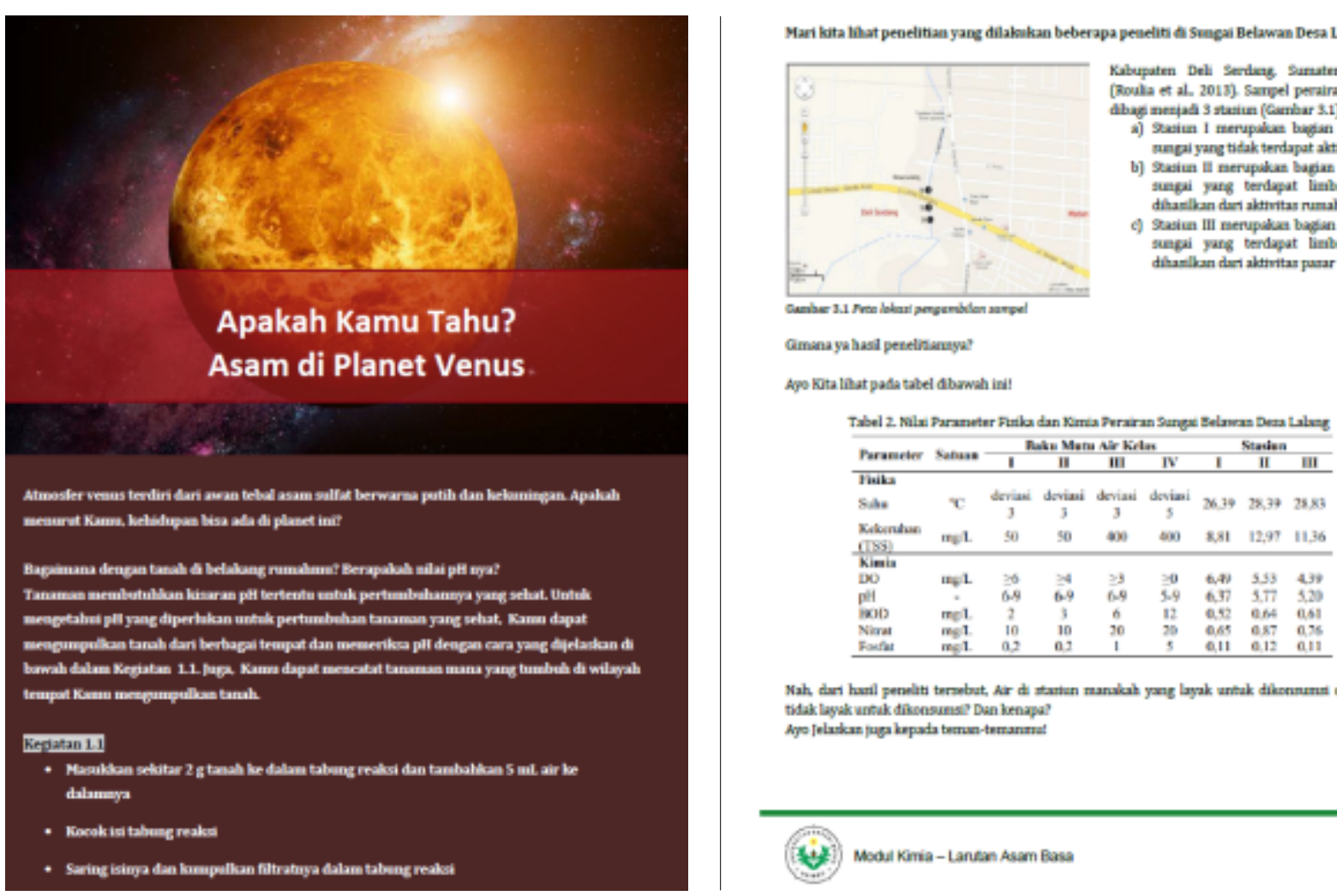

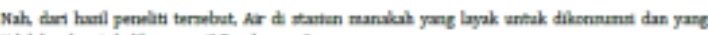



Gambar 1. Beberapa komponen tampilan e-modul asam basa berbasis literasi sains.

Komponen isi e-modul asam basa berbasis literasi sains memiliki nilai rata-rata 4,60 dengan kriteria "sangat layak". Nilai rata-rata ini menunjukkan bahwa e-modul yang dikembangkan sudah sesuai dengan pedoman Kompetensi Inti (KI), Kompetensi Dasar (KD) pada silabus kurikulum 2013 dan layak untuk digunakan siswa dalam proses pembelajaran asam basa.
Komponen penyajian memiliki nilai rata-rata 4,82 dengan kriteria "sangat layak". E-modul yang dikembangkan dibuat berdasarkan indikator dan tujuan pembelajaran yang telah ditentukan. Penyajian e-modul disusun berdasarkan tujuan penerapan 4 aspek literasi sains. Pada e-modul terdapat gambar, video, aktivitas dan pertanyaan terkait materi yang dibahas. Hal ini bertujuan agar siswa memiliki 
motivasi yang lebih dalam belajar dan meningkatkan pemahamannya terhadap materi asam basa. Bahan ajar e-modul juga dilengkapi dengan soal-soal evaluasi. Soal evaluasi digunakan untuk mengukur keberhasilan pencapaian tujuan pembelajaran yang telah dirumuskan ${ }^{[17]}$. Siswa dapat menghitung skor/ hasil akhir yang didapat dengan melihat kunci jawaban yang ada serta pembahasan soal.

Komponen kebahasaan dari e-modul asam basa hasil pengembangan literasi sains memiliki nilai rata-rata 4,57 dengan kriteria "sangat layak". Bahasa yang digunakan dalam e-modul sudah sesuai kaidah bahasa Indonesia yang baik dan benar, komunikatif, dan mudah dipahami. E-modul yang baik menggunakan kalimat yang sederhana sehingga informasi yang disampaikan jelas dan $u s e r$ friendly ${ }^{[18]}$. Penggunaan bahasa yang komunikatif dan sederhana membuat modul mudah dipahami, hal ini diharapkan dapat meningkatkan pemahaman konsep materi asam basa dan minat belajar siswa ${ }^{[19]}$.

Hasil rata-rata keempat aspek literasi sains adalah 4,75 dengan kriteria "sangat layak". Hal ini menunjukkan bahwa pencapaian setiap tujuan dalam empat aspek literasi sains telah terimplementasi dengan baik untuk mengajak siswa berpikir ilmiah, mengidentifikasi pertanyaan serta menarik kesimpulan berdasarkan fakta yang ada. Nilai rata-rata hasil validasi lima aspek penilaian dari 5 validator adalah 4,55; 4,$71 ; 4,74 ; 4,74$; dan 4,77 serta disertai saran dan catatan yang menjadi pedoman untuk perbaikan selanjutnya. E-modul asam basa berbasis literasi sains dikategorikan "sangat layak" dengan skor rata-rata hasil validasi senilai 4,70.

\subsection{Revisi Produk Utama}

Tahap revisi bertujuan untuk menyempurnakan e-modul asam basa berbasis literasi sains yang dianggap masih kurang oleh validator sebelum produk diujicobakan. E-modul yang telah diperbaiki kemudian dikirim ke validator untuk dinilai kembali. Revisi selesai jika e-modul asam basa berbasis literasi sains yang dikembangkan dinyatakan valid oleh validator. Ada beberapa perbaikan yang harus dilakukan antara lain terkait kebahasaan, penyempurnaan gambar, peta konsep, penambahan keterangan gambar dalam bahasa indonesia serta penambahan tabel sistem periodik unsur.

\subsection{Uji Terbatas (Kepraktisan)}

Tahap selanjutnya adalah uji terbatas untuk mendapatkan respons penilaian kepraktisan dari 2 guru kimia dan 20 siswa kelas XI IPA 1 SMA Negeri 10 Medan terhadap bahan ajar e-modul asam basa berbasis literasi sains yang telah dikembangkan. Penilaian dilakukan dengan memberikan angket kepada guru dan siswa.

Berdasarkan hasil analisis data, rata-rata hasil tanggapan guru dari 4 aspek yang terdiri dari aspek minat 4,83 (sangat layak), aspek isi 4,67 (sangat layak), aspek kegunaan 4,38 (sangat layak), dan aspek literasi sains 4,60 (sangat layak). Hasil penilaian dapat dilihat pada Gambar 2. Nilai rata-

\section{Diagram Hasil Penilaian Guru Terhadap e-Modul}

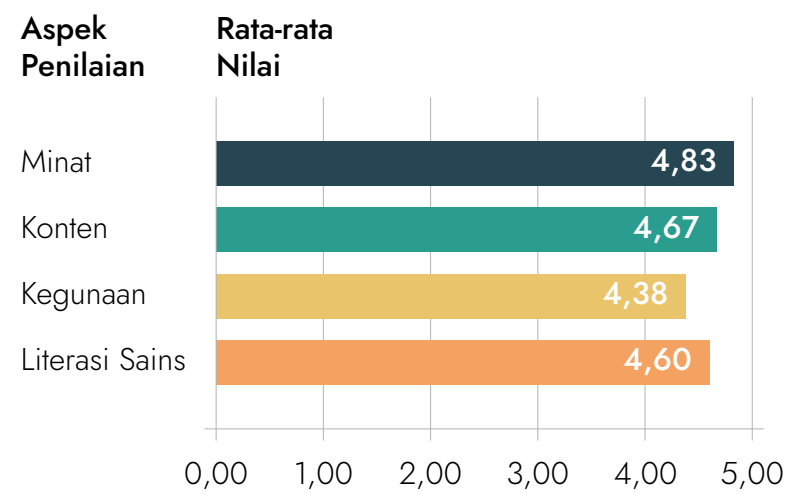

Gambar 2. Diagram Hasil Penilaian Guru terhadap E-Modul.

\section{Diagram Hasil Penilaian Siswa Terhadap e-Modul}



Gambar 3. Diagram Hasil Penilaian Siswa terhadap E-Modul.

rata total jawaban guru adalah 4,60 yang memenuhi kriteria "sangat layak".

Hasil rata-rata respons siswa dari 3 aspek penilaian yaitu pada aspek minat adalah 4,42 (sangat layak), aspek isi 4,08 (layak), dan aspek bahasa 4,50 (sangat layak). Hasil penilaian dapat dilihat pada Gambar 3. Jumlah rata-rata respons siswa terhadap e-modul asam basa berbasis literasi sains hasil pengembangan adalah 4.42 yang memenuhi kriteria "sangat layak". Sehingga secara keseluruhan bahan ajar e-modul asam basa berbasis literasi sains layak untuk digunakan sebagai bahan ajar dalam proses pembelajaran mata pelajaran asam basa.

\subsection{Revisi Produk Operasional}

Tahap terakhir yang dilakukan adalah revisi produk operasional yaitu melakukan perbaikan kedua setelah mendapat penilaian, masukan, kritik serta saran dari guru kimia serta 20 siswa kelas XI IPA 1 SMA Negeri 10 Medan yang bertujuan untuk meningkatkan kelayakan suatu e-modul asam basa berbasis literasi sains untuk digunakan sebagai sumber belajar siswa. 


\section{SIMPULAN}

Berdasarkan hasil analisis dan penelitian, e-modul asam basa berbasis literasi sains dikategorikan "sangat layak" dengan skor rata-rata validasi sebesar 4,70 dan uji kepraktisan melalui respons guru dan siswa sebesar 4,60 dan 4,42.

\section{REFERENSI}

1. OECD. PISA 2012 Results in Focus: What 15 -year-olds know and what they can do with what they know. Programme for International Student Assessment. 2014.

2. Suratsih. Pengembangan Modul Pembelajaran Biologi Berbasis Potensi Lokal Dalam Kerangka Implementasi KTSP SMA di Yogyakarta. Penelitian Unggulan UNY (Multitahun). 2010.

3. OECD. PISA 2018 Results: Combined Executive Summaries Volume I, II, \&III. 2019.

4. Rusilowati A, Nugroho SE, Susilowati SME. Development of Science Textbook Based on Scientific Literacy for Secondary School. J Pendidik Fis Indones. 2016;12(2):98-105.

5. Chiappetta EL, Fillman DA, Sethna GH. A method to quantify major themes of scientific literacy in science textbooks. J Res Sci Teach. 1991; 28(8):713-725.

6. Rokhmah A, Sunarno W, Masykuri M. Science Literacy Indicators in Optical Instruments of Highschool Physics Textbooks Chapter. J Pendidik Fis Indones. 2017;13(1):19-24.

7. Adisendjaja YH. Analisis Buku Ajar Biologi Sma Kelas X Di Kota Bandung. J BIO-UPI; 2010.

8. Bröder J, Okan O, Bauer U, Bruland D, Schlupp $\mathrm{S}$, Bollweg TM, et al. Health literacy in childhood and youth: A systematic review of definitions and models. BMC Public Health. 2017;17(361):1-25.

9. Horton WF. Understanding Understanding information literacy: a primer; an easy-toread, non-technical overview explaining what information literacy means, designed for busy public policy-makers, business executives, civil society administrators and practicing professionals. United Nations Educational, Scientific and Cultural Organization; 2007.

10. Bent, Moira, Stubbing RS. The SCONUL Seven Pillar of Information Literacy: Core Model: For Higher Education; 2011.

11. Nurdyansyah, Fahyuni EF. Inovasi Model Pembelajaran Sesuai Kurikulum 2013. Creative Commons Attribution; 2016.

12. Wijaya JE, Vidianti A. The Effectiveness of Using Interactive Electronic Modules on Student Learning Outcomes in Education Innovation Course. International Conference on Progressive Education (ICOPE 2019). Advances in Social Science, Education and Humanities Research. 2020;422(Icope 2019):86-89.

13. Sugiani KA, Degeng INS, Setyosari P, Sulton. The Effects of Electronic Modules in Constructivist Blended Learning Approaches to Improve Learning Independence. Int $\mathrm{J}$ Innov Creat Chang. 2019;10(9):82-93.

14. Sugiyono. Metode Penelitian Pendekatan Kuantitatif, Kualitatif dan R\&D. Alfabeta; 2015.

15. Husein U. Metode Penelitian untuk Skripsi dan Tesis Bisnis. Jakarta: Rajawali Press; 2011.

16. Depdiknas. Panduan Pengembangan Bahan Ajar. Jakarta: Departemen Pendidikan Nasional Direktorat Jenderal Manajemen Pendidikan Dasar dan Menengah Direktorat Pembinaan Sekolah Menengah Atas; 2008.

17. Suryanto A, Djatmiko T. Konsep Dasar Penilaian dalam Pembelajaran; Eval Pembelajaran di SD. Universitas Terbuka; 2014.

18. Kemendikbud. Panduan Praktis Penyusunan E-Modul. 2017;1-57.

19. Lasmiyati, Harta I. Pengembangan Modul Pembelajaran untuk Meningkatkan Pemahaman Konsep dan Minat SMP. PYTHAGORAS: Jurnal Pendidikan Matematika. 2014;9(2):161-174. 